Álvarez, Rolando y Loyola, Manuel (editores). Un trébol de cuatro hojas. Las Juventudes Comunistas de Chile en el siglo XX. Santiago de Chile: Ariadna y América en Movimiento, 2014, 341 páginas. Camilo Fernández Carrozza

Pp. 277 a 280

\title{
Álvarez, Rolando y Loyola, Manuel (editores). Un trébol de cuatro hojas. Las Juventudes Comunistas de Chile en el siglo XX. Santiago de Chile: Ariadna y América en Movimiento, 2014, 341 páginas.
}

\author{
Camilo Fernández Carrozza*
}

Dentro de la numerosa bibliografía sobre la izquierda chilena aparecida durante los últimos años, poca o ninguna atención han recibido las juventudes de los diversos partidos y movimientos que integraron dicho sector del espectro político. Por ello, Un trébol de cuatro hojas, libro editado por Rolando Álvarez y Manuel Loyola, supone una novedosa incursión en el tema al abordar la trayectoria histórica de las Juventudes Comunistas de Chile (JJ.CC.). Como manifiestan sus editores en la presentación, el libro es un incipiente esfuerzo por revertir el relativo abandono en que se encuentran los estudios históricos sobre organizaciones políticas juveniles en general y de la izquierda en particular. Así, aun cuando las JJ.CC. son una organización eminentemente política, dicho propósito justifica la inclusión de una variedad de temáticas que escapan a lo estrictamente político. Estructurado en dos partes, el libro presenta en su primera sección nueve artículos sobre las JJ.CC. desde sus orígenes hasta la década de los 90, mientras que la segunda parte reúne cinco testimonios de militantes y ex-militantes de la organización. Reconociendo que los estudios incluidos no abarcan la totalidad de la historia de las JJ.CC., Álvarez y Loyola se concentran en sus características y momentos históricos más significativos. No es, pues, una historia de las JJ.CC. propiamente tal, sino un primer paso que busca guiar y ampliar el estudio de las mismas.

Como evidencian los estudios contenidos en el libro, las particularidades de una organización como las JJ.CC. justifican el avanzar en el estudio sobre las juventudes políticas. Marcadas fuertemente por el factor generacional, las juventudes político-partidarias constituyen un fenómeno que no puede reducirse al estudio de sus pares adultos en tanto que la organización de estructuras juveniles significa abrir un campo de acción particular para estas últimas, no siempre al

\footnotetext{
* Investigador asociado Programa de Historia de las Ideas Políticas en Chile, Universidad Diego Portales. Santiago, Chile. Correo electrónico: cfc.15.90@gmail.com
} 
alero de los partidos. Esto implica que las juventudes se desenvuelven en espacios propios, articulando demandas enfocadas a la juventud y desarrollando sus propias formas de socialización, produciendo relaciones a veces complejas entre las filas juveniles y adultas de las organizaciones políticas en términos políticos, ideológicos, organizacionales, culturales, entre otros. Son justamente dichos elementos los que son evidenciados y analizados en los estudios sobre las JJ.CC. contenidos en el libro, que para facilitar su revisión, serán reseñados brevemente de acuerdo a las temáticas que abarcan.

Los primeros tres artículos, "La Juventud Comunista de Chile en los años 20" de Manuel Loyola y Jorge Rojas, "La Federación Juvenil Comunista (19311934) de Manuel Loyola y "Un mundo nuevo contra el fascismo: Las Juventudes Comunistas en tiempos del Frente Popular (1937-1942)" de Nicolás Acevedo, se centran principalmente en la dimensión político-social de los orígenes de las JJ.CC., mostrando los obstáculos presentes en la construcción de una organización política juvenil. Aunque descriptivos en gran parte de su desarrollo, los artículos logran articular los principales hitos y problemáticas que marcaron los inicios de la organización bajo el nombre de Federación Juvenil Comunista. Durante el periodo abarcado, destaca la necesidad de consolidar la organización tanto organizacional como ideológicamente, proceso que ocurre al alero del Partido Comunista (PC) y que se lograría durante los años del Frente Popular. A su vez, dicha subordinación es relativizada por los autores, reconociendo que las JJ.CC. fueron expresión de nuevas formas de socialización enfocadas en formar a los jóvenes para su rol particular la futura construcción del socialismo, identificando constantes tensiones que se desarrollaron entre el PC y sus filas juveniles.

Avanzando en el libro, el artículo "Aire de primavera baña nuestra patria": cancioneros jotosos a inicios de los años 60" de Manuel Loyola se adentra en los aspectos culturales de las JJ.CC., ámbito en que los comunistas tuvieron una destacada presencia durante el siglo XX. Considerando la importancia que los cancioneros tuvieron entre la población joven como expresión de la modernización en el campo cultural, Loyola expone las funciones sociales de los cancioneros en las JJ.CC., acompañando y consolidando la vida militante a la vez que servían al propósito de atraer nuevos militantes y simpatizantes. A pesar de que este texto también tiene un carácter principalmente descriptivo, Loyola proporciona información valiosa para futuros investigadores al recopilar los títulos de numerosas canciones de los cancioneros "jotosos".

El quinto estudio del libro corresponde al de José Ignacio Ponce, "En busca de la universidad democrática. La Jota universitaria durante la reforma de los sesenta". El principal propósito de Ponce es demostrar que las JJ.CC. sí fueron capaces de elaborar un programa propio de carácter democratizador durante la reforma universitaria y su rol no se limitó a la mera disputa por el poder. Es 
destacable que el estudio refleje al mismo tiempo la respuesta de las JJ.CC. a las estrategias del PC a nivel nacional, tanto en su alianza con el Partido Socialista como en las complejas relaciones con la Democracia Cristiana, permitiendo así contrastar la práctica del PC y sus juventudes, cuestión que aparece en numerosos artículos pero que requiere de mayor profundización.

Los siguientes dos textos, el de Carolina Fernández Niño, "Revista Ramona (1971-1973)” y el de Alfonso Salgado, “'Una pequeña revolución'. Las Juventudes Comunistas ante el sexo y el matrimonio durante la Unidad Popular", retoman los aspectos socioculturales de la organización juvenil. Ambos artículos se centran en los cambios culturales asociados a la evidente distancia generacional entre las JJ.CC. y el PC. Por un lado, Fernández Niño muestra cómo, en un contexto de rápido crecimiento de la militancia de las JJ.CC., Ramona lograría ser una forma de expresión cultural y de las inquietudes de la juventud izquierdista del periodo, distanciándose de las publicaciones de carácter político-doctrinaria, plasmando por el contrario, el dinamismo que caracterizaba a los jóvenes comunistas, pero marcando un quiebre generacional con sus pares adultos. En esa misma línea, Salgado mantiene que frente a las temáticas de sexualidad y matrimonio, las JJ.CC. mostraron una postura más abierta que el PC, respondiendo en parte a los cambios de la juventud de la época e iniciado, con sus limitaciones, una "revolución" dentro la cultura comunista caracterizada por su conservadurismo moral. A este respecto, cabe destacar el enfoque utilizado por Salgado, pues a diferencia de otras aproximaciones al tema, que buscan examinar la cuestión de la sexualidad en la izquierda utilizando nuestros parámetros actuales, el autor se interesa más en identificar las rupturas o continuidades que existieron en el periodo, ejemplificadas en las JJ.CC., lo que resalta el valor historiográfico de su estudio.

Los últimos dos artículos, de Rolando Álvarez, "Las Juventudes Comunistas de Chile y el movimiento estudiantil secundario. Un caso de radicalización política de masas (1983-1988)", y de Luis Thielemann, "Hijos de Recabarren, hijos de la transición. Sobre las JJ.CC. y la anomalía estudiantil de los 90", trazan mediante un detallado y riguroso análisis el desarrollo político de la organización en el campo estudiantil (secundario y universitario) durante las décadas de 1980 y 1990. Estos dos últimos estudios pueden resultar particularmente interesantes para los investigadores sobre el tema. Por una parte, a pesar de centrarse en un periodo relativamente reciente, muestran que dichos procesos comienzan adquirir la suficiente distancia histórica para ser abordados satisfactoriamente por la historiografía. Por otro, en el caso particular de los comunistas, el excelente seguimiento de los hechos realizados por ambos autores expone los altos y bajos de lo que fue, y sigue siendo en gran medida, uno de los principales campos de acción de las JJ.CC., revelando sus rupturas y continuidades históricas. 
Finalmente, los cinco testimonios recopilados en la segunda parte del libro constituyen fuentes especialmente útiles para profundizar a futuro los estudios sobre las JJ.CC. Como indican los editores, la importancia de las fuentes testimoniales recae en que estas nos permiten acceder a una variedad de aspectos propios de la militancia, inaccesibles mediante otro tipo de documentación. El sentir de los militantes, sus valoraciones y memorias sobre lo que significó formar parte de una agrupación con una fuerte identidad propia, como es el caso de los comunistas chilenos, sirven sin dudas a investigaciones de diversa índole y aproximaciones.

Para concluir, es posible afirmar que el libro cumple su propósito de incursionar en el estudio de las JJ.CC. Tanto los estudios como los testimonios compilados ofrecen una gran diversidad de aristas para estudiar a dicha agrupación, manteniendo un excelente balance entre los momentos históricos de mayor relevancia y las temáticas más importantes en cada uno de ellos. Del mismo modo, los autores logran desarrollar satisfactoriamente sus análisis mediante la utilización de los enfoques y metodologías adecuadas para la variedad de temas estudiados. A esto cabe añadir que muchos de los estudios se complementan entre sí al tratar sobre contenidos similares, facilitando la utilización del libro para quien desee avanzar sobre alguno de los aspectos que este abarca. No obstante, tanto la calidad como la profundidad de los artículos en su conjunto son dispares. Mientras algunos se mantienen en un nivel descriptivo, limitándose a indicar las cuestiones relevantes sin adentrarse en sus complejidades, otros destacan por lo exhaustivo y elaborado de sus argumentos e investigaciones, proponiendo sus propias interpretaciones y explicaciones. En ese sentido, nivelar las temáticas abordadas en el libro es el desafío que deja el libro para aquellos interesados en la historia de las JJ.CC. 